\title{
Setting up improvement projects in small scale primary care practices: feasibility of a model for continuous quality improvement
}

H Geboers, M van der Horst, $H$ Mokkink, P van Montfort, W van den Bosch, $\mathrm{H}$ van den Hoogen, R Grol

\begin{abstract}
Objectives-To evaluate the feasibility of a model for continuous quality improvement in small scale general practice and the improvement projects that practices ran after the introduction of continuous quality improvement.
\end{abstract}

Design-A descriptive study.

Setting-Twenty general practices in the Netherlands tested the model in an intervention period of 18 months.

Intervention-A model for continuous quality improvement adapted for general practice was introduced into the practices using a structured strategy. Practices were supported by trained facilitators.

Main outcome measures-Acceptance at introduction and continued application of the model; the topics of improvement projects that were set up in the practices; whether the improvement projects had been completed; whether they had met the criteria (the use of the "quality cycle" and the Oxford audit score); and whether the self set objectives had been met.

Results-The model was introduced and accepted in all participating practices. Practices started 51 improvement projects. At the end of the study period 33 improvement projects had been completed. Practices chose a wide variety of objectives for these projects; most of them concerned medical or organisational topics. Practices started projects mainly because the topic was felt to be a problem or was causing a bottleneck in the organisation. The quality cycle was used in all projects, but practices did not always collect data and evaluate the outcomes. Fourteen projects could be discerned as "full audit". No differences existed in the quality of improvement projects among the various types of practice or between the topics addressed. At the end of the study period half of the practices continued applying the model.

Conclusion-This study showed that the model was feasible for small scale general practice. However, application of the model tended to disintegrate after the facilitator had left the practice. Practices succeeded reasonably well in running improvement projects. Introduction of continuous quality improvement should particularly focus on this. It is suggested that intensive support is necessary to implement and maintain continuous quality improvement in small scale practices.

(Quality in Health Care 1999;8:36-42)

Keywords: primary care; continuous quality improvement; improvement projects

Continuous quality improvement is becoming increasingly popular in health care as a model for improving quality. ${ }^{12}$ Continuous quality improvement has advantages over former profession oriented models for quality assurance because it combines managerial and collaboration aspects with a systematic approach..$^{3-5}$ In another paper in this issue we present a model for continuous quality improvement in small scale general practice. This model was based on core elements of continuous quality improvement, which were identified as management, collection of factual data, systematic approach, and collaboration. The model was adapted to the specific characteristics of general practice and simplified as much as possible in an attempt to make it feasible and applicable to general practice. ${ }^{67}$ Box 1 gives an outline of the model. In short, it consists of involving all staff, holding regular meetings on quality, designating a quality coordinator, and writing annual plans and reports on quality improvement. It is crucial to the model that practice teams formulate goals for improvement and attempt to achieve these goals in small scale

Aspects of a model for continuous quality improvement

- Involving all staff

- Setting targets for improvement

- Establishing priorities towards subjects that especially need improvement

- Performing small and easy to handle improvement projects

- Using the quality cycle and easy to use tools and techniques

Favourable changes in the practice organisation

- Having regular practice meetings on quality improvement with all staff

- Enhancing leadership by designating a quality coordinator

- Making annual plans on quality improvement

- Making annual reports on quality improvement activities and results

Box 1 Model for continuous quality improvement in small scale general practice 
improvement projects. A cyclic process (the "quality cycle") is used which leads project teams through the improvement projects. This means that after having chosen a subject that requires attention, the team sets specific targets for the project, analyses the actual performance on the subject, makes and introduces plans for change, and evaluates progress.

Before continuous quality improvement can be accepted and implemented in general practice, its feasibility has to be proved. Experience in larger healthcare organisations has shown that introducing continuous quality improvement is not always easy. ${ }^{8}$ Important indicators for its feasibility are the extent to which the model can be introduced into practices, the extent to which practices continue its application after the introduction, and their ability to run improvement projects in particular. ${ }^{9-12}$ With regard to running improvement projects, it is important to evaluate whether criteria for efficient quality improvement can be met. And if they can be met, which kind of practice is most successful and what kind of topic gives the best opportunity to succeed? Criteria for improvement projects were, for instance, developed by medical audit advisory groups (MAAGs) in the UK. One set of criteria is known as the Oxford audit score. This score is based on the phases of the quality cycle, but it also includes organisational aspects such as the involvement of all staff and repetition of the cycle for future improvement. ${ }^{1314}$

The Centre for Quality of Care Research of the universities of Nijmegen and Maastricht did a study in which the presented model for continuous quality improvement in general practice was evaluated in a small number of practices. In this article we present an evaluation of the feasibility of this model in terms of acceptance at introduction by the general practices and the continued application at the end of the study period. We also evaluate the improvement projects that practices had run and whether criteria for quality for these projects were met. In addition, we evaluate whether the quality of improvement projects varied for types of practice and for kinds of topic addressed.

\section{Methods}

PRACTICES

The study was done on 20 general practices in the Netherlands. Practices were asked to participate in the study via a personal approach, key people, or by mail. The group of participating practices included four single handed practices, 11 duo practices, and five healthcare centres. Single handed refers to practices consisting of one full time general practitioner (GP) and a practice assistant. Duo practices consisted of two GPs and one or two (part time) practice assistants. Single handed and duo practices were all owned and managed by the GPs. Healthcare centres were larger organisations comprising three GPs or more, practice assistants, a district nurse, physiotherapists, and midwives. Healthcare centres were managed by managing directors. None of them were owned by the GPs.
DESIGN

A descriptive study was done over a period of 18 months. Practices were asked to apply all aspects of the model (box 1), to continue its application during the whole period of study, and to start and run small scale improvement projects. They were advised to choose a topic related to diabetes, chronic obstructive pulmonary disease, or hypertension for their first improvement projects. The model was introduced using a structured strategy. Practices were supported by facilitators during the first six months of the study.

\section{Introduction strategy}

The introduction strategy included a meeting with all staff in which the model was explained; a manual on theoretical and practical backgrounds of the model; support in the use of the model and the start of a first improvement project; a one day course on quality management for the quality coordinator and one of the practice assistants; and a practice report containing the results of an audit that was submitted to all practices before participation. This report included data on medical performance, practice organisation, and patient satisfaction.

Two facilitators introduced the model to the participating practices and helped them to use it. The facilitators were former practice assistants who had managerial experience. They were trained in the contents of the model, how to support practices in the use of the model, and in application of the quality cycle and its tools and techniques. All practices were visited by one of the facilitators. They first organised a practice meeting in which the practice report was discussed, the model was explained, and a quality coordinator was designated. Next they made arrangements for monthly quality meetings in which all staff were involved and visited the practices on five subsequent meetings to give them further support. During these meetings they helped practices to set priorities, set up their first improvement project, and use the quality cycle and its tools and techniques.

\section{EVALUATION}

Evaluation took place on two levels: (1) the acceptance at introduction and the continued application of the model and (2) the improvement projects that practices ran, the quality of these projects, and differences between types of practice.

\section{Acceptance at introduction}

Acceptance of the model at introduction was evaluated by measuring the extent to which introduction of the model in the practices actually took place. The facilitators were asked to complete a checklist after each practice visit on which they indicated whether they had given support or made arrangements on various aspects of the model. Items on the checklist included introduction of the model in a special meeting, designation of a quality coordinator, arrangements for subsequent quality meetings, and whether or not priorities were set and an improvement project initiated. 


\begin{tabular}{|ll|}
\hline Code & Description \\
I & Choose topic \\
II & Set target standards \\
III & Observe practice \\
IV & Compare performance with targets \\
V & Implement change, plan care \\
V & Repeat cycle \\
& \\
Citerion & Criterion satisfied if \\
Full audit & Five of six codes present \\
Partial audit & Codes I and III present plus either II or V \\
Potential audit & Codes I and III present \\
Planning audit & Topic chosen and audit definitely intended \\
No audit & \\
\hline
\end{tabular}

Box 2 Oxford audit classification system

They also reported on the topics of the improvement projects.

Continued application of the model

At the end of the 18 months a questionnaire was sent to all practices to measure the extent to which they were still using the model. The questionnaire was addressed to the quality coordinators who had been designated at the introduction. They were asked whether they still retained this quality coordinating function, whether practice staff had set priorities and made plans for future improvements, whether they still held regular quality meetings in which all staff were involved, and whether the practice had written (annual) reports on quality improvement activities.

Performing improvement projects

To gather information on the improvement projects, the quality coordinators were also asked to complete a questionnaire for each improvement project started on account of working with the model for continuous quality improvement. In this questionnaire (a so-called project report) they were asked to describe the topic of each improvement project, the objectives a practice had set, whether or not the phases of the quality cycle had been used, and whether the project had been completed during the period of study. They were asked to describe the plans for change of each improvement project in more detail. The reasons for starting the improvement projects were also recorded. In addition, they were asked to send in the minutes from the quality meetings and the data they had collected from the improvement projects.

Quality of improvement projects

The reports on completed improvement projects were used to evaluate the quality of the improvement projects. They were evaluated on three indicators for quality: the use of the quality cycle, the Oxford audit score, and the extent to which the self set objectives had been met.

Table 1 Continued application of continuous quality improvement at 20 general practices after an introduction period of 18 months

\begin{tabular}{ll}
\hline Aspects of the model & Number of practices \\
\hline A quality coordinator was still in function & 12 \\
Priorities and plans for future improvement had been set & 11 \\
Regular quality meetings were still being held & 10 \\
in which all staff were involved & 9 \\
At least one quality improvement project had been started & 20 \\
at least one had been completed during the introduction period & 17 \\
The practice had written an annual report on quality & 6 \\
\hline
\end{tabular}

The use of the quality cycle in improvement projects was evaluated on the presence of the following aspects of the quality cycle: setting goals for the improvement project, designation of a coordinator for the improvement project, collection of data, analysis of actual processes, plans for change and their introduction, and evaluation of the project.

The Oxford audit score was used as a second quality measure. The score classifies improvement projects as full, partial, potential, planning, or no audit. Specific criteria exist for each level (box 2). These include criteria for success, data collection, and analysis; making plans for change as a result of discussions among doctors or staff; the extent to which goals were achieved; and repetition of the improvement activities.

Whether the self set objectives for the improvement projects had been met was used as a third indicator for the quality of improvement projects. If practices concluded that they had met their objectives, the accuracy of this conclusion was examined by comparing the data that practices had collected with the goals set.

Two researchers independently assessed the Oxford audit score and the self set objectives (agreement $\kappa 0.78$ ) by completing a checklist for each project report. The checklist included items on the criteria of the Oxford audit score and the researchers' judgment on whether the self set objectives had been met. If the project report was not conclusive about the items on the checklist, the researchers used the minutes of the quality meetings for reference.

\section{ANALYSIS}

A descriptive analysis was made of the data on the feasibility of the model. The practice was the unit of analysis. A qualitative analysis was made of the improvement projects that were run. Projects were assigned to one or more of four categories to which they were related: medical performance, practice organisation, equipment and supplies, and services.

A descriptive analysis was also made of the data on the quality of the improvement projects. Contingency tables were made to analyse the relation between the quality of the improvement projects and the types of practice or the categories of the topics chosen.

\section{Results}

ACCEPTANCE AT INTRODUCTION

The facilitators held an introductory meeting in all practices. A quality coordinator was designated in each practice and arrangements for monthly quality meetings were made. The facilitators visited all practices in five subsequent quality meetings, except for two practices in which they were only able to attend four meetings because of the time interval between the meetings at these practices. All practices started by making plans for improvement and setting priorities; they then set up at least one quality improvement project. Healthcare centres invariably started more than one improvement project simultaneously, whereas single 
Table 2 Improvement projects started in 20 practices during the introduction period

\begin{tabular}{|c|c|c|c|c|c|}
\hline Practice & $\begin{array}{l}\text { Type of } \\
\text { practice }\end{array}$ & Topics & Objectives & Completed & $\begin{array}{l}\text { Self set } \\
\text { objectives met }\end{array}$ \\
\hline \multirow[t]{3}{*}{1} & \multirow[t]{3}{*}{$\mathrm{HCC}^{\star}$} & COPD $†$ and asthma in children & $\begin{array}{l}\text { (1) All families who meet the criteria are discussed } \\
\text { by a multidisciplinary team; criteria have been } \\
\text { set for: allergy to mites, insufficient information } \\
\text { given, COPD in patients }<15 \text { years of age, }(2) \text { : } \\
\text { all multidisciplinary teams use the practice } \\
\text { protocol }\end{array}$ & $\mathrm{Y}$ & $\mathrm{Y}$ \\
\hline & & Diabetes & Improve regular check ups & $\mathrm{Y}$ & $\mathrm{N}$ \\
\hline & & Mobility in the elderly & $\begin{array}{l}\text { Improve mobility in the elderly by structured } \\
\text { screening and approach; after home visit by } \\
\text { doctor or district nurse multidisciplinary } \\
\text { discussion about policy }\end{array}$ & $\mathrm{N}$ & \\
\hline \multirow[t]{5}{*}{2} & \multirow[t]{5}{*}{$\mathrm{HCC}$} & Interruptions & $\begin{array}{l}\text { Decrease the number of interruptions by } \\
\text { telephone calls during surgery; criteria to keep } \\
\text { patient satisfaction: urgent matters are dealt } \\
\text { with immediately; patients who insist are put } \\
\text { through to the doctor }\end{array}$ & $\mathrm{Y}$ & $\mathrm{Y}$ \\
\hline & & Supplies & $\begin{array}{l}\text { All supplies needed in the surgery are always } \\
\text { present in large enough quantities; decide which } \\
\text { supplies are needed and to what extent and who }\end{array}$ & 1 & 1 \\
\hline & & & manages supplies & Y & $\mathrm{N}$ \\
\hline & & Surgery & $\begin{array}{l}\text { Make more efficient use of the surgery, task } \\
\text { arrangements between doctors and assistants }\end{array}$ & $\mathrm{N}$ & \\
\hline & & Assignment of tasks & Make practice standards for minor surgery & $\mathrm{N}$ & \\
\hline \multirow[t]{3}{*}{3} & \multirow[t]{3}{*}{$2 \mathrm{GP}$} & Practice leaflet & $\begin{array}{l}\text { Make leaflet; become aware of own wishes and } \\
\text { rules; improve information about tasks of } \\
\text { assistant; explicit practice rules to patients }\end{array}$ & $\mathrm{Y}$ & $\mathrm{Y}$ \\
\hline & & Computerisation & $\begin{array}{l}\text { Improve problem orientated registration in } \\
\text { electronic medical file }\end{array}$ & $\mathrm{N}$ & \\
\hline & & Supplies & $\begin{array}{l}\text { Necessary supplies are available to a sufficient } \\
\text { extent }\end{array}$ & $\mathrm{N}$ & \\
\hline \multirow[t]{10}{*}{4} & \multirow[t]{10}{*}{ HCC } & Low back complaints & $\begin{array}{l}\text { Assign tasks and protocols in patients with low } \\
\text { back pain to GPs and physiotherapists: } \\
\text { uniformity in handling low back pain, decrease } \\
\text { number of patients who become chronically } \\
\text { unable to work }\end{array}$ & $\mathrm{Y}$ & $\mathrm{N}$ \\
\hline & & Vaccination against influenza & $\begin{array}{l}\text { Make and improve scenario for vaccination } \\
\text { against influenza; increase number of indicated } \\
\text { patients that receive a vaccination and improve } \\
\text { the way in which patients are invited }\end{array}$ & $\mathrm{Y}$ & $\mathrm{N}$ \\
\hline & & Financial issues & $\begin{array}{l}\text { Continuously improve the way in which practice } \\
\text { handles invoices and declarations; improvement } \\
\text { strategies based on cases; strive for zero defects }\end{array}$ & $\mathrm{N}$ & \\
\hline & & Appointment schedule & $\begin{array}{l}\text { Continuously improve the way of handling } \\
\text { appointments and demands for appointments; } \\
\text { improve the division of surgery hours between }\end{array}$ & & \\
\hline & & & GPs; computerisation of appointment schedule & $\mathrm{N}$ & \\
\hline & & Diabetes & $\begin{array}{l}\text { Continuously improve diabetes care; make } \\
\text { practice standard; improve compliance with } \\
\text { regular check ups (to improve blood glucose } \\
\text { concentrations is not the aim in first quality } \\
\text { cycle) }\end{array}$ & $\mathrm{N}$ & \\
\hline & & Hypertension & $\begin{array}{l}\text { Continuously improve hypertension care; make } \\
\text { protocol on risk factors, improve compliance } \\
\text { with regular check ups (to improve blood } \\
\text { pressure is not the aim in first quality cycle) }\end{array}$ & $\mathrm{N}$ & \\
\hline & & COPD & $\begin{array}{l}\text { Classify patients into optimal and less optimal } \\
\text { tuning; within the first quality cycle COPD of } \\
30 \text { patients has to become optimally tuned }\end{array}$ & $\mathrm{N}$ & \\
\hline & & Familiar carcinoma of the breast & $\begin{array}{l}\text { Prevention and early diagnosis of familiar } \\
\text { carcinoma of the breast based on a control scheme } \\
\text { made up of risk factors }\end{array}$ & $\mathrm{N}$ & \\
\hline & & Cervical smears & Improve the compliance rate with cervical smears & $\mathrm{N}$ & \\
\hline 5 & 2 GP & Overrunning surgery & Reduce overrunning time for surgery & $\mathrm{Y}$ & $\mathrm{N}$ \\
\hline \multirow[t]{5}{*}{6} & \multirow[t]{5}{*}{$1 \mathrm{GP}$} & Training of practice assistant & $\begin{array}{l}\text { Improve the functioning of practice assistant by } \\
\text { training }\end{array}$ & $\mathrm{Y}$ & $\mathrm{Y}$ \\
\hline & & Cervical smears & $\begin{array}{l}\text { Delegate smears taken for the national programme } \\
\text { to practice assistant; set criteria for quality }\end{array}$ & $\mathrm{Y}$ & $\mathrm{Y}$ \\
\hline & & COPD & $\begin{array}{l}\text { All patients have regular check ups (once in } 3 \\
\text { months) (medication (compliance), peak flow, } \\
\text { health) }\end{array}$ & $\mathrm{Y}$ & $\mathrm{N}$ \\
\hline & & Vaccination against influenza & $\begin{array}{l}\text { Increase the number of patients who are } \\
\text { vaccinated against influenza }\end{array}$ & $\mathrm{Y}$ & $\mathrm{N}$ \\
\hline & & Collaboration with pharmacist & Improve communication with pharmacist & $\mathrm{Y}$ & $\mathrm{N}$ \\
\hline \multirow[t]{4}{*}{7} & \multirow[t]{4}{*}{$2 \mathrm{GP}$} & Cervical smears & $\begin{array}{l}\text { Increase the expertise of the practice assistant } \\
\text { taking cervical smears; practice assistant fulfils } \\
\text { the tasks for national programme }\end{array}$ & $\mathrm{Y}$ & $\mathrm{Y}$ \\
\hline & & Diabetes & $\begin{array}{l}\text { Diabetes check ups by the practice assistant: (1) } \\
\text { all patients have to be examined according to } \\
\text { the national standard and (2) make task } \\
\text { arrangements between doctor and assistant }\end{array}$ & $\mathrm{Y}$ & $\mathrm{N}$ \\
\hline & & Vaccination against influenza & Increase the rate of indicated patients who receive & & \\
\hline & & & influenza vaccination & $\mathrm{Y}$ & $\mathrm{N}$ \\
\hline \multirow[t]{2}{*}{8} & \multirow[t]{2}{*}{$1 \mathrm{GP}$} & Cervical smears & Decrease the number of smears without & $\mathrm{Y}$ & $\mathrm{Y}$ \\
\hline & & Hypertension & $\begin{array}{l}\text { (1) } 50 \% \text { of all hypertension check ups are done by } \\
\text { the practice assistant; (2) consultation about } \\
\text { changes in medication; (3) continuity; and (4) } \\
\text { professionalism }\end{array}$ & $\mathrm{Y}$ & $\mathrm{N}$ \\
\hline
\end{tabular}


Table 2 Continued

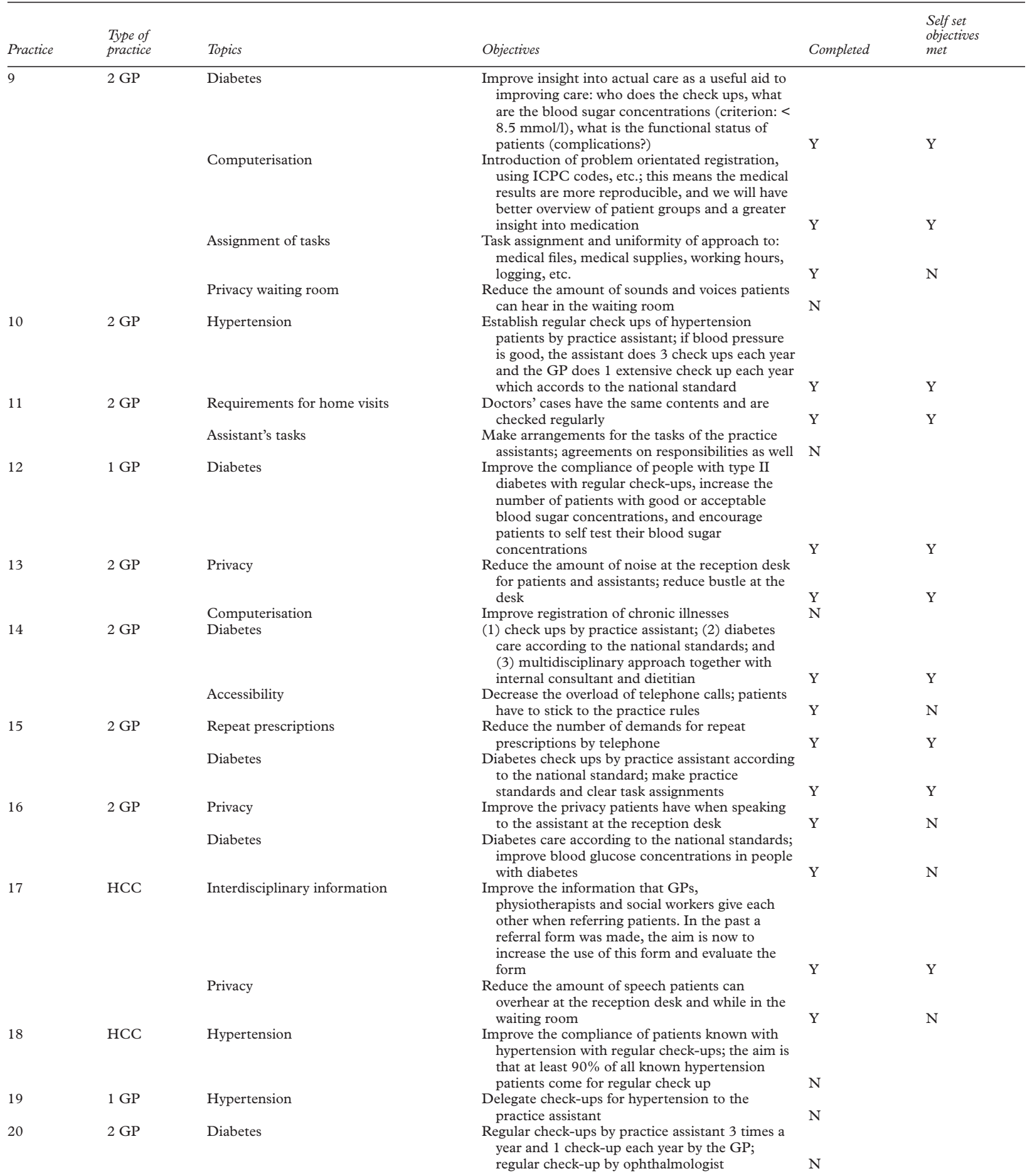

${ }^{\star}$ Type of practice: HCC: Health care centre; 2 GP: duo practice; 1 GP: single-handed practice. $+\mathrm{COPD}=$ chronic obstructive pulmonary disease.

handed and duo practices started only one improvement project at a time.

\section{CONTINUED APPLICATION}

The questionnaire which evaluated the extent to which practices continued applying the model at the end of the period of study was returned by 17 practices ( $85 \%$ ) (table 1$)$. In slightly more than half of the practices a quality coordinator was still in place, priorities and plans for future improvement had been set, and regular quality meetings were still being held. At the end of the study most of the participating practices had succeeded in fully completing at least one improvement project.

IMPROVEMENT PROJECTS

During the study period 51 improvement projects were started. At the end of the study 33 projects had been completed, while 18 were still running. Table 2 shows the subjects and objectives of the improvement projects that 
Table 3 Reasons for starting improvement projects in 20 practices

\begin{tabular}{ll}
\hline Reasons for starting an improvement project & $\begin{array}{l}\text { Number of projects } \\
(n=51)\end{array}$ \\
\hline Subject was felt to be a bottleneck in practice & 28 \\
Subject is a national guideline (implementation of NHG-standard) & 12 \\
Subject was chosen because of the outcomes in the practice report & 8 \\
Subject was chosen because of a case presented in practice & 5 \\
Subject was a complaint or an idea from a patient or others & 3 \\
Priorities to chose the subject were set outside practice (e.g. GP group) & 2 \\
Subject was chosen because of the outcomes of a patient survey & 1 \\
Subject was chosen because of other reasons & 23 \\
\hline
\end{tabular}

^Practices could have more than one reason for starting an improvement project.

Table 4 Quality of completed improvement projects $(n=33)$ and the extent to which self set objectives had been met

\begin{tabular}{ll}
\hline Quality measures & $\begin{array}{l}\text { Number of } \\
\text { projects }\end{array}$ \\
\hline Phases of quality cycle & \\
Goals set & 32 \\
Coordinator designated & 32 \\
Data collected & 27 \\
Analysis of change made & 25 \\
Plans for change made & 30 \\
Changes introduced & 30 \\
Results evaluated & 25 \\
Oxford audit score & \\
Full audit & 14 \\
Partial audit & 6 \\
Potential audit & 1 \\
Planning audit & 12 \\
Objectives met & 18 \\
\hline
\end{tabular}

were run by the participating practices. Practices chose a wide variety of subjects and objectives for improvement projects. Many of the improvement projects concerned medical issues such as diabetes care, hypertension care, cervical smears, vaccination for influenza, chronic obstructive pulmonary disease, carcinoma of the breast, low back pain, and mobility of the elderly. Practices often tried to improve medical performance by changing the processes by which the GP and assistant cooperated (practice organisation). They developed practice protocols or task agreements. In many projects, especially the ones done by single handed practices, delegation of tasks to the practice assistant was the goal. Other topics, which were chosen less often, included equipment and supplies, improving the practice building, or computerisation. Projects in which the aim was to improve the service to patients almost invariably concerned improving privacy at the reception desk or in the waiting room.

Table 5 Differences in the quality of improvement projects between types of practice and kinds of topic chosen

\begin{tabular}{lrlr}
\hline & \multicolumn{3}{l}{$\begin{array}{l}\text { Quality of } \\
\text { improvement } \\
\text { projects }\end{array}$} \\
\cline { 2 - 4 } & & $\begin{array}{l}\text { Full } \\
\text { Oxford } \\
\text { audit }\end{array}$ & Objectives \\
& Number \\
of projects & score & met \\
\hline Type of practice & & & \\
Single handed & 8 & 3 & 4 \\
Duo practice & 17 & 7 & 10 \\
Healthcare centre & 8 & 4 & 4 \\
Kind of topic & & & \\
Medical & 18 & 10 & 10 \\
Organisational & 23 & 9 & 13 \\
Service & 8 & 4 & 3 \\
Infrastructure & 6 & 2 & 3 \\
Total & 33 & 14 & 18 \\
\hline
\end{tabular}

^Projects could be assigned to more than one category of topics.
Table 3 presents the reasons for starting an improvement project; practices often had more than one reason for starting one. Reasons that were reported most often included "the subject chosen was felt to be a problem or a bottleneck in practice management", "the practice wanted to implement the national guidelines (on that specific topic)", and "the outcomes of the audit report". Practices had several other reasons for starting improvement projects such as a practice assistant had asked for it, a GP had just started it, or a GP had a special interest in the subject. In other cases the subject was part of the managerial plan of the practice. One of the projects was started because a new GP was appointed; another was started because the practice had commenced with computerisation.

\section{QUALITY OF IMPROVEMENT PROJECTS}

Table 4 shows the quality measures for completed improvement projects. The quality cycle had been used fully in 16 out of $33(52 \%)$ completed projects. Collecting data on actual care and analysing them, and evaluating the improvement project as a whole had been used less often than the other aspects of the quality cycle. In 14 projects the criteria for full audit on the Oxford audit score was met, and in six additional projects the criteria for partial audit was met. In 18 out of 33 (55\%) projects the self set objectives were met. Of the 17 practices that had completed at least one improvement project, 12 had full audit as best performance and 15 had managed to meet the self set objectives in at least one improvement project.

Table 5 shows the quality of improvement projects for the various types of practice and the topics chosen. The degree to which the Oxford audit score was met and the objectives achieved were similar in the various types of practice and topic.

\section{Discussion}

The results show that it is possible to set up continuous quality improvement in small scale general practice with (at least some) motivated GPs and staff. At the end of the study half of the practices continued to apply the model. After 18 months, it proved to be possible for most of the practices to bring at least one improvement project to an end. These results seem to be comparable with those of other studies. In a study in England, seven out of 18 practices had completed projects and a further six had ongoing ones, and 11 of 18 practices said they intended to use continuous quality improvement principles in the future. ${ }^{3}$

If we look at the quality of the improvement projects, it proved possible for practices to run improvement projects in the correct way. The systematic approach of the quality cycle was used reasonably well, although practices did have some difficulties in gathering data and evaluating progress in the improvement projects. No striking differences existed in performance between single handed practices, duo practices, and healthcare centres in running improvement projects, and the topics chosen did not seem to be related to the quality of the improvement project. 
Some limitations of this study should be kept in mind. Firstly, our study group comprised a limited number of motivated practices. This implies that performance at other practices may not be as good, or that they may need more support and facilitation to complete projects and to perform according to the model for continuous quality improvement. Secondly, these improvement projects were the first the practices had ever run using this approach. It is likely that practices would have done better if they had got previous experience with improvement projects. Thirdly, because of the limited number of practices and the absence of a control group, no conclusions can be made towards the influence of the introduction strategy or the facilitators. One might expect that these factors play a rather big part. On the other hand, these influences could be regarded as inevitable at the first introduction of continuous quality improvement. Finally, the strategy we used to introduce continuous quality improvement was the most we could do with the resources available. The results might have been better if a more extensive strategy had been used.

Some of our observations will help to implement continuous quality improvement in general practice. Firstly, practices tended to choose organisational objectives for their first improvement projects. In many of the projects the main objective was to change practice processes in a specific way. Presently, some of these changes are quite fashionable in general practice in the Netherlands, such as creating a consulting hour for the practice assistant in which she does regular checkups on patients with diabetes and hypertension. This seems to be in accordance with previous findings where improvement of the internal structure is often seen as the first step towards the full adoption of continuous quality improvement. ${ }^{15}{ }^{16}$ It is sensible therefore to advise practices to start with this kind of improvement project: practices can gain some experience in running improvement projects, the subjects fit in with their direct needs, and the changes concerned are often practical and not complex, which provides greater opportunities for instant success. Secondly, we found that, although practices had started enthusiastically, maintaining a high level of commitment was not always realistic, which led to partial disintegration of working with the model after the facilitator had left the practice. On the other hand, practices all selected one or more topics and started to run improvement projects. Although they found it hard to use some aspects of the quality cycle, they did not seem to have any reluctance to start improvement projects when facilitated. Finally, with a restricted although realistic budget, facilitation should be set up as efficiently and effectively as possible. Staying close to the needs and expectations of the practices could be a way to introduce continuous quality improvement more effectively. To further enhance facilitation of continuous quality improvement in general practice, it is important to investigate how practices value continuous quality improvement and its various aspects.

It can be concluded that continuous quality improvement is feasible in small scale general practice. If sufficient facilitation and support are provided, practices will probably be able to succeed in adopting the principles of continuous quality improvement. Introduction of continuous quality improvement should first focus on running improvement projects- practices perform best on that aspect-because this provides practices with the most concrete opportunities to improve and the best chances for success.

1 Berwick DM. Heal thyself or heal thy system. Quality in Health Care 1992;1(suppl):S2-8.

Health Care 1992;1(suppl):S2-8.
Berwick DM. A primer on leading the improvement of systems. BMF 1996;312:619-22.

3 Lawrence M, Packwood T. Adapting total quality management for general practice: evaluation of a programme. Quality in Health Care 1996;5:151-8.

4 Baker R. Audit and the team: an interview with the Adelaide medical centre team. Quality in Health Care 1993;2:191-4.

5 Chambers R, Bowyer S, Campbell I. Audit activity and quality of completed audit projects in primary care Staffordshire. Quality in Health Care 1995;4:178-83.

6 Geboers H, Van de Bosch W, Van den Hoogen H, et al. A model for continuous quality improvement in small scale practices. Quality in Health Care 1999;8:43-8.

7 Gustafson DH, Schoofs Hundt A. Findings of innovation research applied to quality management principles for health care. Health Care Management Review 1995;20:1633.

8 Shortell SM, O'Brien JL, Carman JM, et al. Assessing the impact of continuous quality improvement/total quality management: concept versus implementation. Health Services Research 1995;30:377-401.

9 Merry MD. Total quality management for physicians. Translating the new paradigm. Qual Rev Bull 1990;16:101-

10 Baird R. The implementation of total quality. In: Al-Assaf AF, Schmele JA, editors. Textbook of total quality in health care. Delray Beach, Florida: St Lucie Press, 1993:91-101.

11 Batalden PB. A framework for the continual improvement of health care. Building and applying professional improvehealth care. Building and applying professional improvement knowledge to test changes in dail

12 Swanson TK, Eilers GM. Physician and staff acceptance of CQ. Fam Med 1994;26:583-6.

13 Derry J, Lawrence M, Griew K, et al. Auditing audits: the method of Oxfordshire medical audit advisory group. BMF 1991;303:1247-9.

14 Chambers R, Bowyer S, Campbell I. Audit activity and quality of completed audit projects in primary care in Staffordshire. Quality in Health Care 1995;4:178-83.

15 Woollass T. First steps in TQM. Audit Trends 1994;2:77-9.

16 Wagner C, de Bakker DH, Sluijs EM. Kwaliteitssystemen in instellingen: de stand van zaken. Utrecht: Nivel, 1995. 